\title{
Cardiovascular magnetic resonance characterization of peri-infarct zone remodeling following myocardial infarction
}

\author{
Karl H Schuleri ${ }^{1}$, Marco Centola ${ }^{1,2}$, Kristine S Evers ${ }^{1}$, Adam Zviman ${ }^{1}$, Robert Evers ${ }^{1,3}$, João AC Lima ${ }^{1}$ and \\ Albert C Lardo ${ }^{1,4^{*}}$
}

\begin{abstract}
Background: Clinical studies implementing late gadolinium-enhanced (LGE) cardiovascular magnetic resonance (CMR) studies suggest that the peri-infarct zone (PIZ) contains a mixture of viable and non-viable myocytes, and is associated with greater susceptibility to ventricular tachycardia induction and adverse cardiac outcomes. However, CMR data assessing the temporal formation and functional remodeling characteristics of this complex region are limited. We intended to characterize early temporal changes in scar morphology and regional function in the PIZ.

Methods and results: CMR studies were performed at six time points up to 90 days after induction of myocardial infarction (MI) in eight minipigs with reperfused, anterior-septal infarcts. Custom signal density threshold algorithms, based on the remote myocardium, were applied to define the infarct core and PIZ region for each time point. After the initial post-MI edema subsided, the PIZ decreased by $54 \%$ from day 10 to day 90 ( $p=0.04$ ). The size of infarct scar expanded by $14 \%$ and thinned by $56 \%$ from day 3 to 12 weeks ( $p=0.004$ and $p<0.001$, respectively). LVEDV increased from 34.7. $\pm 2.2 \mathrm{ml}$ to $47.8 \pm 3.0 \mathrm{ml}$ (day3 and week12, respectively; $p<0.001$ ). At 30 days post-MI, regional circumferential strain was increased between the infarct scar and the PIZ $(-2.1 \pm 0.6$ and $-6.8 \pm 0.9$, respectively; $p<0.05$ ).
\end{abstract}

Conclusions: The PIZ is dynamic and decreases in mass following reperfused MI. Tensile forces in the PIZ undergo changes following MI. Remodeling characteristics of the PIZ may provide mechanistic insights into the development of life-threatening arrhythmias and sudden cardiac death post-MI.

Keywords: Cardiovascular magnetic resonance imaging, Myocardial infarction, Late gadolinium enhancement, Periinfarct zone, Myocardial strain

\section{Background}

Despite substantial progress in risk stratification to identify susceptible patients and therapeutical advances, the risk of sudden death remains the highest in the first 30 days after myocardial infarction (MI) [1,2]. Estimates from recent clinical trials show an annualized suddendeath risk of $8 \%$ to $12 \%$ in the 3 -month period after MI, even with optimal medical therapy [3]. Myocardial scar tissue is one of the most important structural substrates for sudden cardiac death. It has been demonstrated that

\footnotetext{
* Correspondence: al@jhmi.edu

'Johns Hopkins School of Medicine, Division of Cardiology, 1042 Ross Building, Baltimore, MD 21205, USA

Full list of author information is available at the end of the article
}

islands of viable myocardium - surrounded by regions of myocardial scar -can produce the substrate for monomorphic ventricular tachycardia (VT), which is a significant risk factor for sudden cardiac death [4].

Recent studies employing late gadolinium enhancement (LGE) CMR suggest that a mixture of viable and non-viable cells can be identified as the peri-infarct zone (PIZ), due to an intermediate CMR intensity level between normal (black) and infracted (white) myocardium. Although the detection of the PIZ is contributed to the partial volume effect in CMR acquisitions $[5,6]$, this "grey zone" has been shown to be a predictor of post-MI mortality. Patients with a large PIZ volume are

\section{() Biomed Central}


more susceptible to VT induction, and have worse cardiac outcomes $[7,8]$.

However, PIZ data correlating tissue, substrate-specific characteristics of the temporal formation and functional remodeling of the PIZ, which occur concurrently with structural LV chamber remodeling, do not exist. The purpose of this study was to test the hypothesis that the peri-infarct zone undergoes spatial and functional changes over time in parallel with structural ventricular remodeling following reperfused MI.

\section{Methods}

\section{Animal model}

All animal studies were approved by the Johns Hopkins University Institutional Animal Care and Use Committee and comply with the "Guide for the Care and Use of Laboratory Animals" (NIH Publication no. 80-23, revised 1985). Fourteen female Göttingen minipigs, at $15 \pm 1$ months of age, were purchased from Marshall BioResources (North Rose, NY). Myocardial infarcts were created in a closed chest approach by 120 minutes balloon occlusion of the left anterior descending artery, followed by restoration of flow, as described in detail previously [9]. One animal did not survive the infarct procedure and 4 animals died during the follow-up period at day 3, day 4, day 30, and day 90 . One Göttingen minipig could not be imaged at all time points because of poor venous accessibility.

\section{Cardiac magnetic resonance imaging protocols}

CMR images were acquired sequentially - prior to the infarction procedure - at baseline (BSN) and at 3, 10, 30, 60, and 90 days post MI, using a $1.5 \mathrm{~T}$ MR scanner (CV/i, GE Medical Systems, Waukesha, WI).

Global LV function was assessed using a steady-state free precession pulse sequence with breath-holding acquisitions [10]. A total of six to eight contiguous short-axis slices were prescribed to cover the entire LV from base to apex. Image parameters were as follows: $\mathrm{TR} / \mathrm{TE}=4.2 \mathrm{~ms} / 1.9 \mathrm{~ms} ;$ flip angle $=45^{\circ} ; 256 \times 160$ matrix; $8 \mathrm{~mm}$ slice thickness/no gap; $125 \mathrm{kHZ;} 28 \mathrm{~cm}$ FOV and 1 NSA.

To assess circumferential strain (Ecc), CMR tagged images were acquired with an electrocardiography-gated, segmented K-space, fast gradient- recalled- echo pulse sequence with spatial modulation of magnetization, to generate a grid tagged pattern [11,12]. Images were obtained at the same location as the cine-CMR images with image parameters as follows: TR/TE $=6.7 \mathrm{~ms} / 3.2$ $\mathrm{ms}$; flip angle $=12 ; 256 \times 160$ matrix, views/s: $4 ; 8-\mathrm{mm}$ slice thickness/no gap; $31.25 \mathrm{kHz} ; 28 \mathrm{~cm}$ FOV; 1 NSA; and 6 pixels tagging space.

After an intravenous injection of Gd-DTPA $(0.2 \mathrm{mmol} /$ kg body weight, Magnevist, Berlex, Wayne, NJ), LGE
CMR images were acquired 15 minutes later using an ECG-gated, breathhold, interleaved, inversion recovery, FGRE pulse sequence. LGE- CMR images were acquired in the same location as the short axis cine-images. Imaging parameters were $\mathrm{TR} / \mathrm{TE} / \mathrm{TI}=7.3 \mathrm{~ms}, 3.3 \mathrm{~ms}$ and 180 to $240 \mathrm{~ms}$; Flip angle $=25^{\circ} ; 256 \times 196$ matrix; $8 \mathrm{~mm}$ slice thickness/no gap; $31.2 \mathrm{kHZ;} 28 \mathrm{~cm}$ field of view (FOV) and 2 NSA. Inversion recovery time was adjusted as needed to null the normal myocardium [13].

\section{CMR image analysis}

CMR images, covering the entire ventricle, were analyzed using a custom research software package (Cine Tool, GE Medical Systems, Waukesha, WI). Infarct size and infarct mass in the LGE- CMR images were defined based on 3 standard deviations of the signal intensity from the remote mean (non-infarct) myocardium for the core infarct, and 2 standard deviations of the signal intensity from the remote mean for the PIZ; the fullwidth half-max (FWHM) method was also applied, as described in detail previously $[6,7,14]$. Infarct remodeling parameters were evaluated on delayed contrast enhanced CMR images using commercially available imaging analysis software (Sigma Scan ${ }^{\circledR}$ Pro5, Systat Software Inc., San Jose, CA). Infarct expansion and thinning were defined as follows:

$$
\begin{aligned}
& \text { Expansion Index }=\frac{\text { endocardial length of the infarct scar }}{\text { endocardial length of the whole ventricle }} \\
& \text { Thinning Ratio }=\frac{\text { Thickness of infarct zone }}{\text { Thickness of remote zone }}
\end{aligned}
$$

Cine CMR images were analyzed with QMass $M^{\circledR}{ }^{\circledR}$ (Medis medical imaging systems, Leiden, The Netherlands). To evaluate global left ventricular (LV) function and volumes, and LV wall motion and wall thickness, endoand epicardial borders of the LV were defined in the enddiastolic and end-systolic frame in contiguous slices, and then LV parameters and volumes were calculated. We assessed contraction in the mid-wall layer of 24 circumferential locations of the LV myocardium. Tagged images were quantitatively analyzed with a custom software package (Diagnosoft HARP, Diagnosoft Inc., Palo Alto, CA), as described in detail previously [15]. The peak systolic circumferential strain (Ecc) was determined from the strain map of each point. Negative Ecc values represent myocardial contraction, whereas values of increasing strain (toward positive values) reflect worsening of cardiac contractile function in that region. Less negative Ecc values represent hypokinetic myocardium. A value of 0 represents akinetic non-contractile myocardium, whereas a positive value represents dyskinetic myocardial segments.

For follow-up analysis, short axis LGE CMR images were compared to regional strain values. Images were divided in to 24 segments for detailed analysis. Regional 
strain values were matched with the infarct, PIZ, and remote areas, defined by LGE CMR images. Mechanical segmental dysfunction was then assessed by the circumferential strain uniformity ratio estimate (CURE) measurement, as previously described [16,17]. Briefly, circumferential strain (y-axis) was plotted versus sector position for the 24 evenly distributed segments in each slice (x-axis), and subjected to Fourier analysis. A perfectly synchronous ventricle provides a CURE value of 1 , whereas for a perfectly dyssynchronous heart the CURE index is 0. Although the CURE index has been used previously to quantify dyssynchrony in the whole ventricle, we applied this method to index segmental dysfunction.

\section{Statistical analysis}

All data are presented as mean \pm standard error of the mean. Our data sets show Gaussian distribution. Follow-up data were analyzed using repeated measures of one way analysis of variance (ANOVA). Tukey's post hoc analysis was performed to compare variables at different time points. Strain values of infarct and PIZ were evaluated with a paired Student's t-test; $P$-values $<0.05$ were considered significant. All analyses were performed with commercially available software (GraphPad Software, LaJolla, CA)

\section{Results}

We studied 8 minipigs sequentially with CMR and established that all enrolled animals followed the natural history of cardiac remodeling, after the index event, as described previously [18]. Changes in LVEF, LV volumes, and LV-mass are summarized in Table 1.

\section{Temporal changes of the PIZ}

Three days post MI the infarct territory was large, accompanied by the largest peri-infarct zone detected by
CMR (Figure 1). At 10 days, the infarct territory and the PIZ decreased by $28 \pm 5 \%$ percent and $46 \pm 6 \%$ percent, respectively - using the 2 and 3 standard deviations threshold. We also applied the FWHM criterion and found a decrease from $5.9 \pm 0.5$ gram to $3.5 \pm 0.4$ gram at day 3 to day 10, respectively, $(\mathrm{p}<0.001)$ - which represent a $39.6 \%$ in PIZ. There were no differences in decrease with either method ( $\mathrm{p}=0.41)$. The myocardial scar expanded and thinned until day 90, consistent with ongoing remodeling processes (Table 2). The infarct scar mass decreased until week 4 , and then modestly increased thereafter in accordance with infarct expansion. In contrast, the PIZ decreased continuously until day 90 . The results of the absolute and derived values for the infarct size and the peri-infarct zone - using the 2 and 3 standard deviation threshold - are shown in Figures 2 and 3. The PIZ analyzed with the FWHM criterion followed the same pattern.

\section{Regional parameters of remodeling}

We examined wall motion and end-diastolic wall thickness as regional remodeling parameters by using the American Heart Association 17-segment model. As shown in Figure 4, the end-diastolic wall thickness initially increased after acute MI, in the infarcted territories, and then decreased over time in parallel with a loss of regional function. We analyzed the course of myocardial function in the PIZ in detail by following single slices over time (Figure 4). Since the 17-segment model averages data from large sectors of the left ventricle, we focused on regional strain analysis in single slices divided by the 24 segments (Figure 5). At day 30, Ecc showed increased strain values in the PIZ, compared to the infarct scar $(p<0.05)$, which is consistent with a tethering effect (of the infarct scar on the viable myocytes) in the PIZ (Figure 5). The time to peak strain also

Table 1 Animal characteristic and left ventricular performance

\begin{tabular}{|c|c|c|c|c|c|c|c|}
\hline & BSN & Day 3 & Day 10 & Day 30 & Day 60 & Day 90 & $p$-value \\
\hline LVEF (\%) & $52.7 \pm 1.3$ & $47.0 \pm 2.4$ & $43.3 \pm 2.2$ & $41.2 \pm 2.0$ & $38.1 \pm 2.9$ & $39.1 \pm 2.8$ & $<0.001$ \\
\hline LVSV (ml) & $21.0 \pm 0.9$ & $16.0 \pm 0.8$ & $16.8 \pm 0.8$ & $16.3 \pm 1.1$ & $17.6 \pm 2.0$ & $19.2 \pm 1.9$ & 0.03 \\
\hline LVEDV (ml) & $40.3 \pm 2.5$ & $36.0 \pm 2.5$ & $39.2 \pm 1.9$ & $39.8 \pm 2.6$ & $46.3 \pm 3.6$ & $49.4 \pm 3.5$ & 0.002 \\
\hline LVESV (ml) & $19.3 \pm 1.7$ & $19.8 \pm 2.1$ & $22.4 \pm 1.7$ & $23.5 \pm 2.0$ & $28.7 \pm 2.7$ & $30.2 \pm 2.7$ & $<0.001$ \\
\hline LVED mass (gram) & $32.1 \pm 1.5$ & $34.7 \pm 1.7$ & $34.4 \pm 2.4$ & $32.3 \pm 1.6$ & $35.8 \pm 1.6$ & $38.6 \pm 1.8$ & 0.01 \\
\hline BW (kg) & $30.8 \pm 1.5$ & $29.7 \pm 1.4$ & $32.0 \pm 1.8$ & $31.7 \pm 1.0$ & $33.9 \pm 1.2$ & $35.1 \pm 1.7$ & 0.1 \\
\hline
\end{tabular}

LVEF left ventricular ejection fraction, LVSV left ventricular systolic volume, LVEDV left

ventricular end-diastolic volume, LVESV left ventricular end-systolic volume, $B W$ body

weight $B S N$ baseline (CMR prior to $\mathrm{MI}$ )

${ }^{*} p<0.05$ versus $\mathrm{BSN}$

$+p<0.01$ versus BSN

${ }^{\ddagger} p<0.01$ versus Day 3

$\S p<0.05$ versus Day 3

${ }^{\|} p<0.05$ versus Day 10

ๆ $p<0.05$ versus Day 30 


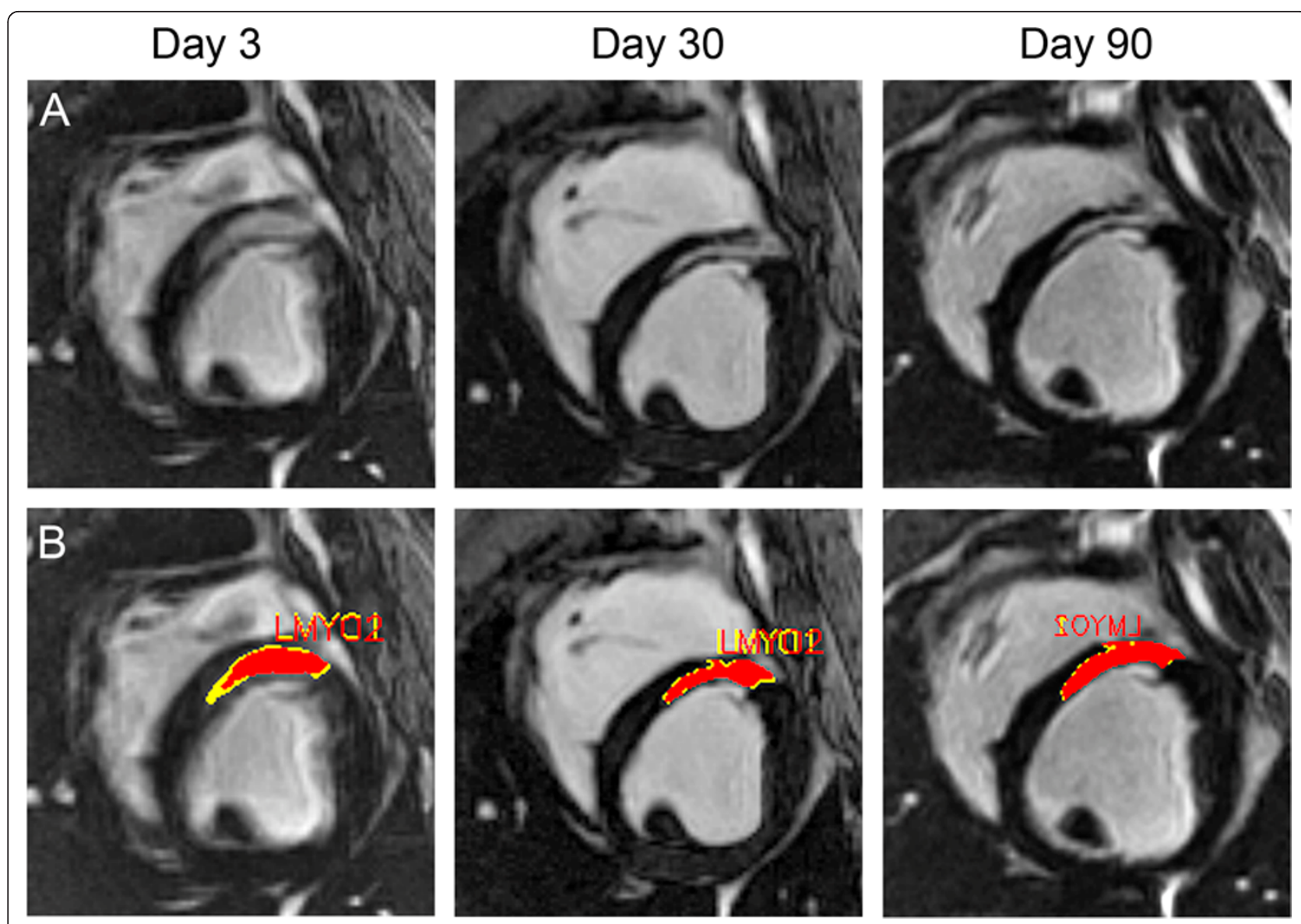

Figure 1 Remodeling of the peri-infarct zone (PIZ) assessed by LGE-CMR. (A) Example of one myocardial short axis slice followed over time until day 90 post-MI.(B) The same myocardial slices with computer - generated mask depicting the core infarct (red) and PIZ (yellow). The PIZ is most pronounced on day 3 and diminishes thereafter. After day 30 only little change in extent of the PIZ can be observed with CMR imaging.

showed a delay between the infarct scar and the PIZ $(203.0 \pm 11.9 \mathrm{~ms}$ vs.171.2 $\pm 7.4 \mathrm{~ms}$, respectively; $p<$ 0.05). In addition, segmental contractive dysfunction, quantified by CURE, was increased acutely after MI (BSN vs day3; $p<0.05$ ) and showed the most dysfunction 30 days post MI, represented by the lowest CURE value $(0.74 \pm 0.06)$.

\section{Discussion}

This is the first report to use CMR to characterize PIZ remodeling after myocardial infarction. There are two major findings in this study: 1) temporal changes in PIZ size can be detected with LGE-CMR, and 2) myocardial strain patterns change during the post-MI remodeling process.

Post-MI remodeling and the underlying substrate for PIZimaging

Cardiac wound repair, after MI, involves temporarily overlapping phases which include an inflammatory phase and tissue remodeling phase. The first phase starts shortly after coronary artery occlusion- with or

Table 2 Left ventricular remodeling indices

\begin{tabular}{lcccccc}
\hline & Day 3 & Day 10 & Day 30 & Day 60 & Day 90 & $\boldsymbol{p}$ - Value \\
\hline $\begin{array}{l}\text { Expansion } \\
\text { Index }\end{array}$ & $3.4 \pm 0.29$ & $3.21 \pm 0.22$ & $3.76 \pm 0.31$ & $3.72 \pm 0.30$ & $4.30 \pm 0.47^{* \dagger}$ & 0.01 \\
\hline Thinning Ratio & $1.3 \pm 0.10$ & $1.19 \pm 0.11$ & $0.92 \pm 0.05^{\ddagger \S}$ & $0.90 \pm 0.04^{\ddagger \S}$ & $0.77 \pm 0.06^{\ddagger \dagger}$ & $<0.01$ \\
\hline
\end{tabular}

* $p<0.05$ versus Day 3

${ }^{+} p<0.01$ versus Day 10

${ }^{\ddagger} p<0.01$ versus Day 3

${ }^{\S} p<0.05$ versus Day 10 


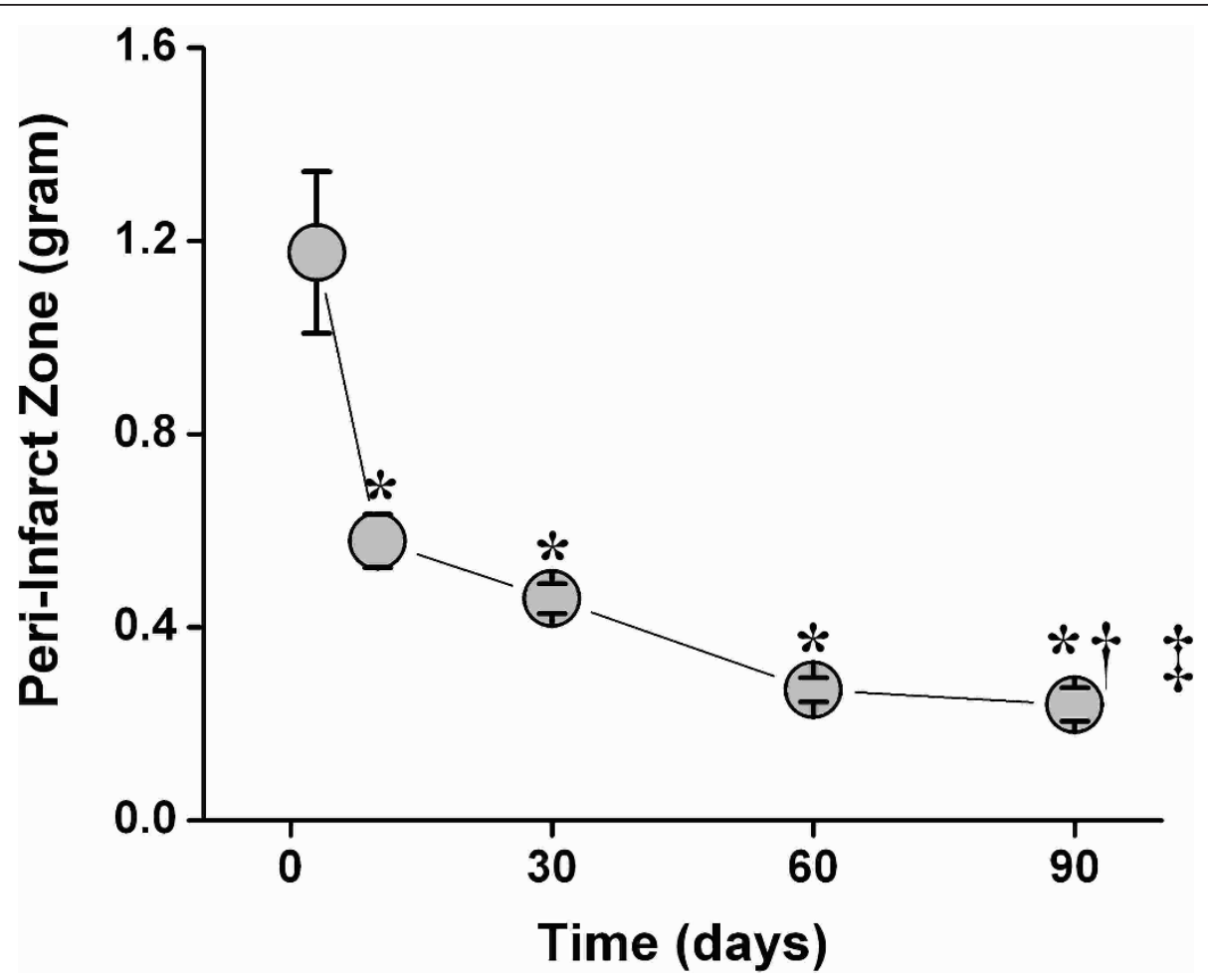

Figure 2 PIZ remodeling over $\mathbf{9 0}$ days assessed by LGE-CMR imaging. (A) The PIZ mass decreased consecutively until 90 days post-MI. The most pronounced drop was observed from day 3 to day 10 . PIZ- mass decreased gradually until day 60 , and only showed a minimal changes between day 60 and $90{ }^{*} p<0.01$ versus day 3 post Ml; ${ }^{+} p<0.05$ versus day 10 post Ml; repeated measures of ANOVA $\left.{ }^{\star} p<0.001\right)$.

without reperfusion- and involves degradation of normal extracellular matrix, invasion of inflammatory cells at the site of initial injury, and the induction of bioactive peptides and cytokines [19]. Therefore, the early imaged MI substrate is characterized by a high cellularity, which is replaced by dense collagen fibers. These synthetic and degradative events, within the myocardial extra-cellular matrix, occur in a time and region-dependent manner following MI - which is reflected by histological and ultrastructural morphological changes. Within the MI region, the newly formed scar provides a means to tether viable myocyte fascicles, and thereby forms a substrate to resist deformation from the intra-cavitary stresses, generated during the cardiac cycle $[20,21]$.

\section{LGE-CMR imaging and PIZ assessment}

Early CMR acquisitions for infarct size quantification in the acute phase are complicated by post-MI edema, which leads to an overestimation of the exact MI-size. Although the assessment of the PIZ may be influenced by the tissue edema, the PIZ (by CMR) still reflects the mixture of viable and infarcted myocardium.

Different techniques for analysis have been previously used to determine the PIZ in CMR. Specifically, the assessment of the PIZ is either defined with threshold techniques using standard deviations to the remote myocardium [8], or based on modified FWHM criterion applying different signal intensities [7,22]. All of these methods claim to match the visual assessment of the PIZ by LGE-CMR. However, with the lack of quantitative histological reference, standard to index the heterogeneity of the PIZ, it is difficult to determine which method is superior over the other. In our analysis, we chose to use the 2 and 3 standard deviations threshold for this report and we found the best agreement with our visual assessment of the PIZ on LGE CMR images. In addition, we quantitatively assessed the PIZ with the FWHM criterion and found a similar remodeling pattern. We discovered that the quantified PIZ mass was larger with the FWHM method, compared to the threshold technique - which confirms previous reports $[7,8]$.

CMR has been used for risk stratification for ventricular arrhythmias following MI. Studies conducted in the 1980s show that a low LVEF predicts the risk of death after MI [23,24], and this data is currently used as one of the main criteria for ICD implantation [25]. Subsequent studies demonstrate that infarct surface area and mass- measured by CMR- can more accurately identify patients at risk and present a substrate for monomorphic VT, when compared to LVEF [26]. The ability 


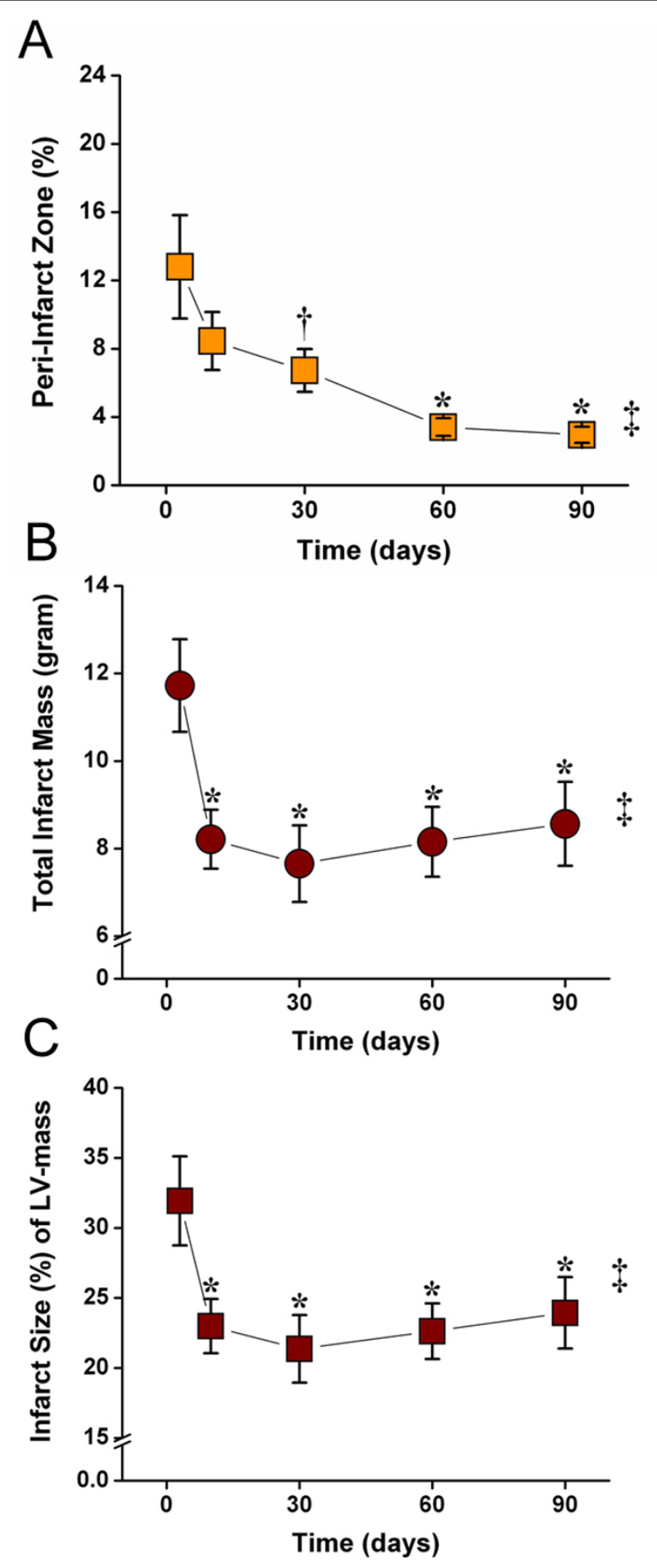

Figure 3 LGE-CMR values of PIZ and infarct size remodeling. PIZ expressed as percent of total infarct size decreased until day 60 , and only showed a minimal changes between day 60 and $90{ }^{*} p<0.01$ versus day 3 post $\mathrm{Ml}^{*}{ }^{\dagger} p<0.05$ versus day 3 post Ml; repeated measures of ANOVA ${ }^{*} p<0.001$ ).(B) Absolute and (C) relative values of the infarct size show a continuous decline of infarct size until day 30 . After 30 days the infarct mass and size increases until day 90 Consistent with infarct expansion (* $p<0.01$ versus day 3 post Ml; repeated measures of ANOVA $\neq p<0.001)$. 

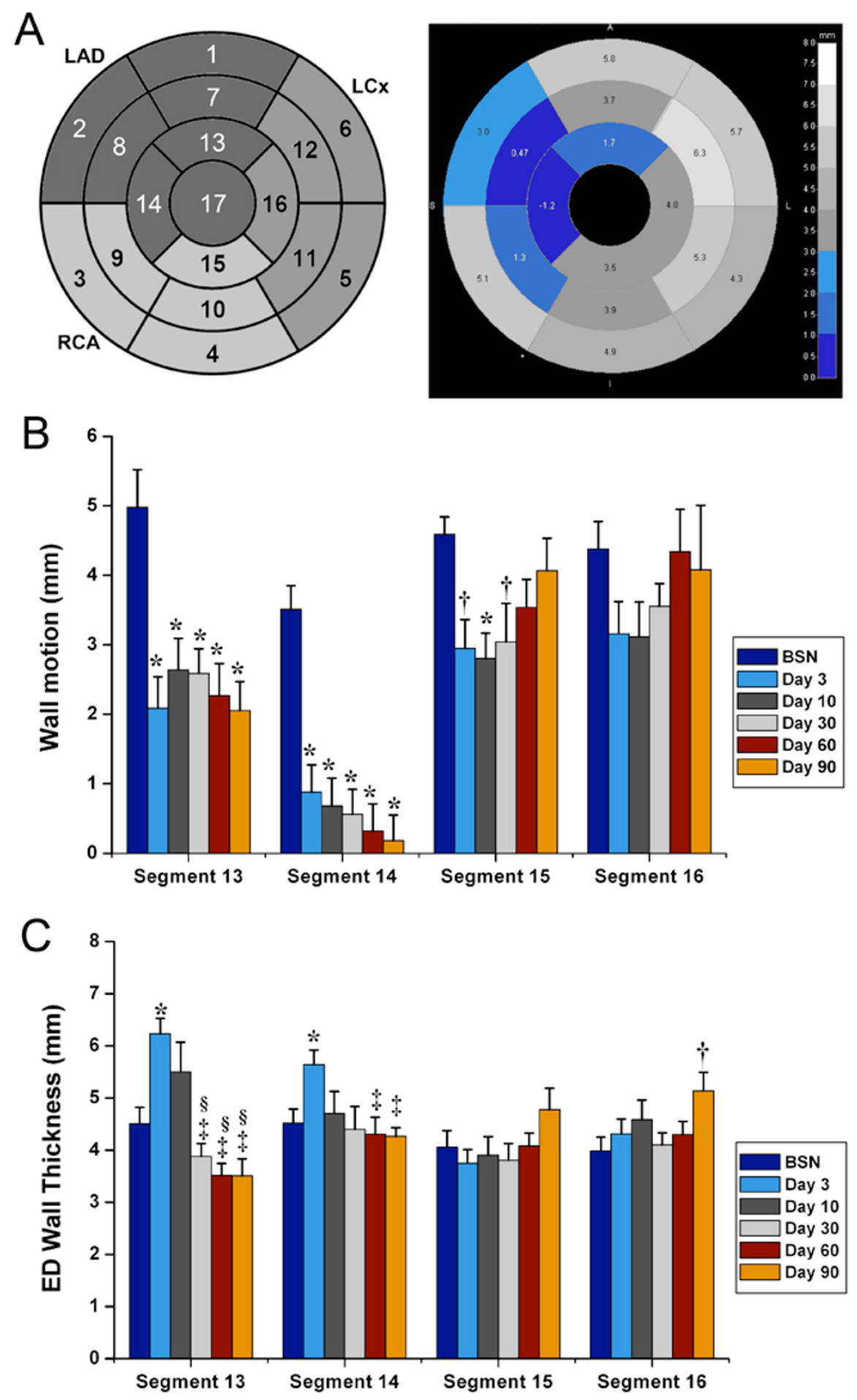

Figure 4 Regional remodeling of the left ventricle after myocardial infarction. (A) Wall motion (ES-ED wall thickness) and endiastolic (ED) wall thickness of the whole left ventricle expressed in 17-segment model in relation to coronary artery supply. The polar plot on the right is an example of wall motion at 90 days post-MI. The reduced wall motion in the apical and mid-wall region in the LAD territory is revealed by the different shades of blue. (B) Wall motion in the apical segments decreases continuously during the 90 day follow-up in the infracted LAD territory (segment 13 and $14 ;{ }^{*} p<0.01$ versus baseline [BSN]; CMR acquisitions prior to MI), while it only decreases initially in the non-infarct related arteries (segment $15 ;{ }^{*} p<0.01$ versus $\mathrm{BSN}^{+} p<0.05$ versus BSN) and recovers during the follow-up ( $p=$ NS versus BSN). (C) ED wall thickness increase with post-MI edema in segments 13 and $14\left(^{*} p<0.01\right.$ versus BSN) and decreases after edema has been absorbed $\left(^{\ddagger} p<0.01\right.$ versus Day $3,{ }^{\S} p<0.05$ versus Day 10). ED wall thickness of segment 16 at day 90 indicates compensatory hypertrophy of the remote, noninfarcted territory, to compensate for the thinning infarct scar $\left({ }^{\dagger} p<0.05\right.$ versus BSN). 

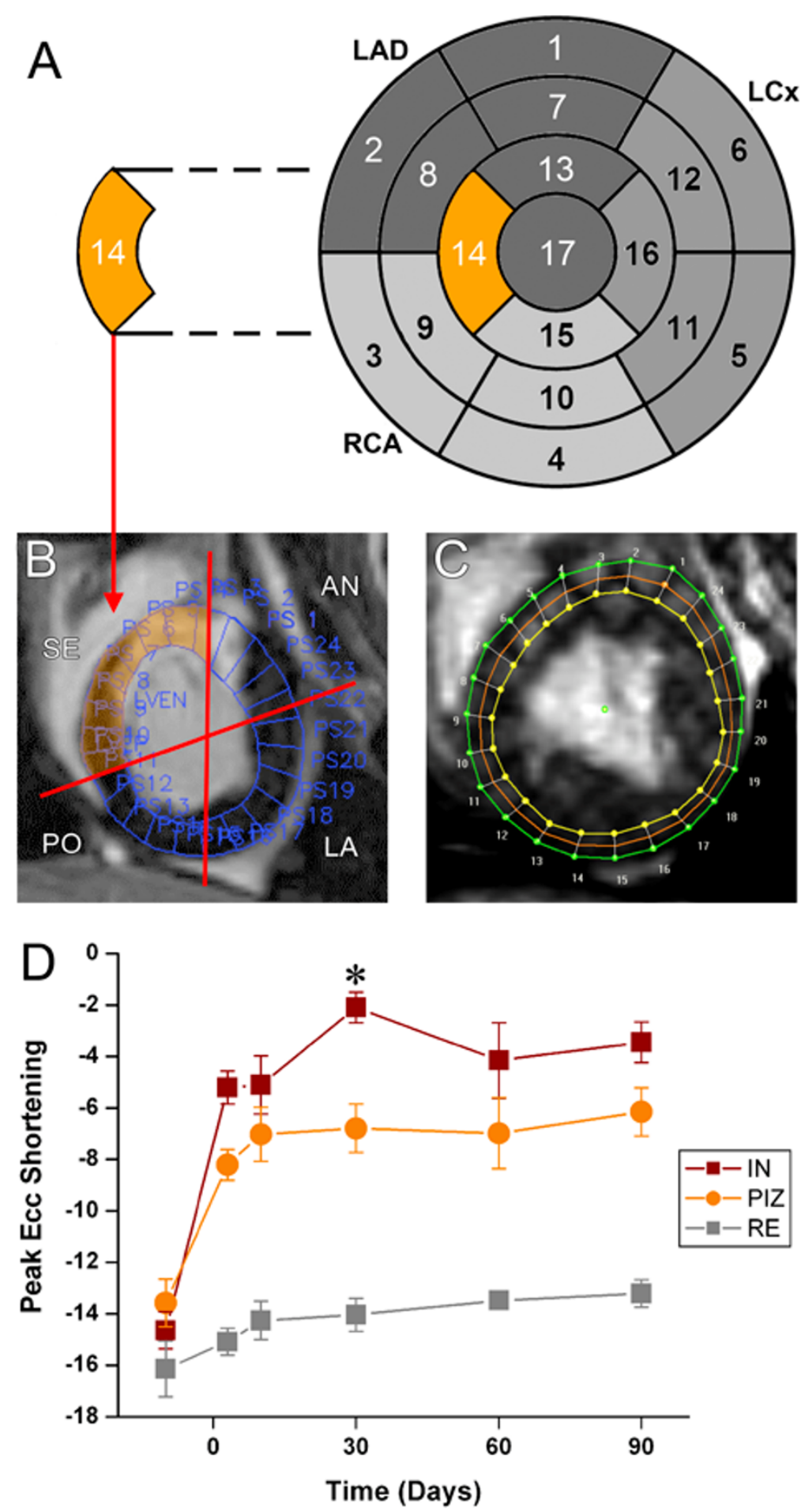

Figure 5 Strain analysis in the peri-infarct zone in short axis slices. (A) The 17-segment analysis provides an overview regional function in the whole left ventricle. (B) However, data from the infarct, the PIZ and non-infarcted areas have to be combined, and are therefore averaged. The septal (SE) area highlighted in orange represents segment 14. (SE = septal; $A N=$ anterior; $L A=$ lateral; $P O=$ posterior). (C,D) To assess regional strain in the PIZ we sub-divided the short axis slices in 24 segments and matched each segment with the corresponding segment from the tagging analysis for Ecc and Err analysis, respectively.(D) At 30 days post-MI peak Ecc is different between the infarct scar tissue (IN) and the $\mathrm{PIZ}\left({ }^{*} p<0.05\right.$ versus IN). (F) At 3 days and 30 days post-MI the Err shows different strain values in the IN and $\mathrm{PIZ}\left({ }^{*} p<0.05\right.$ versus IN). (RE $=$ remote moyocardium, $\mathrm{PIZ}=$ peri-infarct zone, $\mathrm{IN}=$ myocardial infarct scar). 
to perform more detailed morphological analysis of the infarct scar will allow refined information on risk stratification $[7,8]$.

Histologically, the early period of remodeling is characterized by the ongoing changes of the extracellular matrix and cell composition of tissue scar substrate, whereas the later period is characterized by a fixed substrate of cardiomyoctes and well-defined collagen scar [ref]. We demonstrate that the PIZ-assessed by LGECMR imaging- undergoes significant changes early after MI as well. Until day 10, the PIZ decreases rapidly in mass and the PIZ mass stabilizes thereafter. Our data suggests that after 4 weeks post- MI, the PIZ can reliably evaluate structural remodeling. Additional information for regional strain analysis was acquired, which provides valuable information about the tensile forces working on the scar tissue and in the PIZ.

Recently, Fernandes et al. showed that enhanced PIZ function, defined as greater Ecc and earlier time to peak Ecc, was associated with inducibility in patients with post MI heart failure [27]. In our research, we did not see enhanced PIZ function at any particular time point during the remodeling process up to 90 days. However, at 30 days post-MI, we did observe a significant difference in Ecc and time to peak Ecc, between the infarct scar and PIZ, suggesting heightened mechanical stress working at the interface of viable and infarct tissue (Figure 6) $[28,29]$. Tensile forces working on the viable myocytes - neighboring the scar tissue - have been proposed for decades as crucial patho-physiological mechanisms, involved in post-MI remodeling and infarct expansion [18]. Until now, this concept could not be experimentally verified using non-invasive imaging methods. A recent study demonstrated that circumferential strain rates are independent predictors of outcomes after MI and are predictive of cardiac remodeling following MI [30]. However, Sasano et al. reported the highest inducibility in a porcine model, 30 days after MI-induction [31]. This is the same time-point that we observed the highest difference of strain between infracted area and PIZ in our pigs. The study of Sasano et al. and our findings suggest that the underlying pathophysiology (of post-MI VT) can be elucidated with imaging techniques.

\section{Limitations}

The most significant limitation in this animal study was the inability to perform serial VT inducibilty studies with programmed stimulation. Having this data would help to determine the relationship between the imaged tissue substrate and susceptibility to VT. Another limitation was that all of the infarcts were created in the LAD territory, and were transmural. Strain patterns in the PIZ for non-transmural infarcts are expected to be very different from those in transmural infarcts, but our research did not explore this theory. Further, we did not acquire T2-weighted CMR images to quantify the post-MI edema, nor did we use any medications that are currently administered to patients in the post-MI period.

\section{Conclusions}

The PIZ is a complex tissue substrate that changes its composition and decreases in mass, following reperfused MI. The difference in tensile strain forces, between the infarct scar and the PIZ, is reached approximately 30 days after MI. After this time, the underlying tissue substrate is mainly composed of viable myocytes and clear defined collagen tissue. Myocardial strain characteristics, combined with the PIZ for the assessment of LGE-CMR images, may provide important clinical information for the development of life-threatening arrhythmias, as well as sudden cardiac death post-MI.

\section{Abbreviations}

BSN: Baseline; CMR: Cardiovascular magnetic resonance; CURE: Circumferential strain uniformity ratio estimate; Ecc: Circumferential strain; Err: Radial strain; FWHM: Full-width half max; LGE: Late gadolinium enhancement; LV: Left ventricle/ventricular; LVEDV: Left ventricular enddiastolic volume; LVESV: Left ventricular end-systolic volume; LVEF: Left ventricular ejection fraction; LVSV: Left ventricular systolic volume; MI: Myocardial infarction; PIZ: Peri-infarct zone; RE: Remote myocardium; VT: Ventricular tachycardia.

\section{Acknowledgements}

This work was supported by NIH grant U54 HL081028, and The Donald W. Reynolds foundation. The authors thank Norman J. Barker, M.S., R.B.P. for his expertise and helpful suggestions presenting images and data visually.

\section{Author details}

${ }^{1}$ Johns Hopkins School of Medicine, Division of Cardiology, 1042 Ross Building, Baltimore, MD 21205, USA. ${ }^{2}$ Azienda Ospedaliera San Paolo, Polo Universitario, Milan, Italy. ${ }^{3}$ Radiology and Imaging Sciences, National Institutes of Health (NIH), Bethesda, MD, USA. ${ }^{4}$ Department of Biomedical Engineering, Johns Hopkins University, Baltimore, MD, USA.

\section{Authors' contributions}

KHS, planned, and performed experiments, supervised CMR acquisitions, analyzed data and images, and wrote the manuscript. MC planned, and performed experiments. KSE and AZ performed imaging analysis. RE acquired CMR data. JACL edited the manuscript. ACL supervised imaging analysis, and edited the manuscript. All authors read and approved the final manuscript.

\section{Competing interests}

The authors declare that they have no competing interests.

Received: 20 December 2011 Accepted: 17 April 2012

Published: 17 April 2012

\section{References}

1. Bunch TJ, Hohnloser SH, Gersh BJ. Mechanisms of sudden cardiac death in myocardial infarction survivors: insights from the randomized trials of implantable cardioverter-defibrillators. Circulation. 2007;115(18):2451-7. doi:10.1161/CIRCULATIONAHA.106.683235.

2. Solomon SD, Zelenkofske S, McMurray JJ, Finn PV, Velazquez E, Ertl G, Harsanyi A, Rouleau JL, Maggioni A, Kober L, White H, Van de Werf F, Pieper K, Califf RM, Pfeffer MA. Sudden death in patients with myocardial 
infarction and left ventricular dysfunction, heart failure, or both. $N$ Engl J Med. 2005;352(25):2581-8. doi:10.1056/NEJMoa043938.

3. Pitt B, Remme W, Zannad F, Neaton J, Martinez F, Roniker B, Bittman R, Hurley S, Kleiman J, Gatlin M. Eplerenone, a selective aldosterone blocker, in patients with left ventricular dysfunction after myocardial infarction. N Engl J Med. 2003;348(14):1309-21. doi:10.1056/NEJMoa030207.

4. Goldberger JJ, Passman R. Implantable cardioverter-defibrillator therapy after acute myocardial infarction: the results are not shocking. J Am Coll Cardiol. 2009;54(22):2001-5. doi:10.1016/j.jacc.2009.08.018.

5. Schelbert EB, Hsu LY, Anderson SA, Mohanty BD, Karim SM, Kellman P, Aletras AH, Arai AE. Late gadolinium-enhancement cardiac magnetic resonance identifies postinfarction myocardial fibrosis and the border zone at the near cellular level in ex vivo rat heart. Circ Cardiovasc Imaging. 2010;3(6):743-52. doi:10.1161/CIRCIMAGING.108.835793.

6. Schuleri KH, Centola M, George RT, Amado LC, Evers KS, Kitagawa K, Vavere AL, Evers R, Hare JM, Cox C, McVeigh ER, Lima JA, Lardo AC. Characterization of periinfarct zone heterogeneity by contrast-enhanced multidetector computed tomography: a comparison with magnetic resonance imaging. J Am Coll Cardiol. 2009;53(18):1699-707. doi:10.1016/j. jacc.2009.01.056.

7. Schmidt A, Azevedo CF, Cheng A, Gupta SN, Bluemke DA, Foo TK Gerstenblith G, Weiss RG, Marban E, Tomaselli GF, Lima JA, Wu KC. Infarct tissue heterogeneity by magnetic resonance imaging identifies enhanced cardiac arrhythmia susceptibility in patients with left ventricular dysfunction. Circulation. 2007;115(15):2006-14. doi:10.1161/ CIRCULATIONAHA.106.653568.

8. Yan AT, Shayne AJ, Brown KA, Gupta SN, Chan CW, Luu TM, Di Carli MF, Reynolds HG, Stevenson WG, Kwong RY. Characterization of the peri-infarct zone by contrastenhanced cardiac magnetic resonance imaging is a powerful predictor of postmyocardial infarction mortality. Circulation. 2006:114(1):32-9. doi:10.1161/CIRCULATIONAHA.106.613414.

9. Schuleri KH, Boyle AJ, Centola M, Amado LC, Evers R, Zimmet JM, Evers KS, Ostbye KM, Scorpio DG, Hare JM, Lardo AC. The adult Gottingen minipig as a model for chronic heart failure after myocardial infarction: focus on cardiovascular imaging and regenerative therapies. Comp Med. 2008;58 (6):568-79.

10. Slavin GS, Saranathan M. FIESTA-ET: high-resolution cardiac imaging using echoplanar steady-state free precession. Magn Reson Med. 2002;48 (6):934-41. doi:10.1002/mrm.10321.

11. Lima JA, Ferrari VA, Reichek N, Kramer CM, Palmon L, Llaneras MR, Tallant B, Young AA, Axel L. Segmental motion and deformation of transmurally infarcted myocardium in acute postinfarct period. Am J Physiol. 1995;268(3 Pt 2):H1304-12.

12. Zerhouni EA, Parish DM, Rogers WJ, Yang A, Shapiro EP. Human heart: tagging with MR imaging-a method for noninvasive assessment of myocardial motion. Radiology. 1988;169(1):59-63.

13. Simonetti OP, Kim RJ, Fieno DS, Hillenbrand HB, Wu E, Bundy JM, Finn JP, Judd RM. An improved MR imaging technique for the visualization of myocardial infarction. Radiology. 2001;218(1):215-23.

14. Amado LC, Gerber BL, Gupta SN, Rettmann DW, Szarf G, Schock R, Nasir K, Kraitchman DL, Lima JA. Accurate and objective infarct sizing by contrastenhanced magnetic resonance imaging in a canine myocardial infarction model. J Am Coll Cardiol. 2004;44(12):2383-9. doi:10.1016/j.jacc.2004.09.020.

15. Amado LC, Schuleri KH, Saliaris AP, Boyle AJ, Helm R, Oskouei B, Centola M, Eneboe V, Young R, Lima JA, Lardo AC, Heldman AW, Hare JM. Multimodality noninvasive imaging demonstrates in vivo cardiac regeneration after mesenchymal stem cell therapy. J Am Coll Cardiol. 2006;48(10):2116-24. doi:10.1016/j.jacc.2006.06.073.

16. Helm RH, Leclercq C, Faris OP, Ozturk C, McVeigh E, Lardo AC, Kass DA. Cardiac dyssynchrony analysis using circumferential versus longitudinal strain: implications for assessing cardiac resynchronization. Circulation. 2005;111(21):2760-7. doi:10.1161/CIRCULATIONAHA.104.508457.

17. Byrne MJ, Helm RH, Daya S, Osman NF, Halperin HR, Berger RD, Kass DA, Lardo AC. Diminished left ventricular dyssynchrony and impact of resynchronization in failing hearts with right versus left bundle branch block. J Am Coll Cardiol. 2007;50(15):1484-90. doi:10.1016/j.jacc.2007.07.011.

18. Pfeffer MA, Braunwald E. Ventricular remodeling after myocardial infarction. Experimental observations and clinical implications. Circulation. 1990;81 (4):1161-72. doi:10.1161/01.CIR.81.4.1161
19. Spinale FG. Myocardial matrix remodeling and the matrix metalloproteinases: influence on cardiac form and function. Physiol Rev. 2007;87(4):1285-342. doi:10.1152/physrev.00012.2007.

20. Zimmerman SD, Criscione J, Covell JW. Remodeling in myocardium adjacent to an infarction in the pig left ventricle. Am J Physiol Heart Circ Physiol. 2004;287(6):H2697-704. doi:10.1152/ajpheart.00160.2004.

21. Omens JH, Miller TR, Covell JW. Relationship between passive tissue strain and collagen uncoiling during healing of infarcted myocardium. Cardiovasc Res. 1997;33(2):351-8. doi:10.1016/S0008-6363(96)00206-4.

22. Roes SD, Borleffs CJ, van der Geest RJ, Westenberg JJ, Marsan NA, Kaandorp TA, Reiber JH, Zeppenfeld K, Lamb HJ, de Roos A, Schalij MJ, Bax JJ. Infarct tissue heterogeneity assessed with contrast-enhanced MR predicts spontaneous ventricular arrhythmia in patients with ischemic cardiomyopathy and implantable cardioverterdefibrillator. Circ Cardiovasc Imaging. 2009;2(3):183-90.

23. Risk stratification and survival after myocardial infarction. N Engl J Med. 1983;309(6):331-6.

24. Bigger JT Jr, Fleiss $\mathrm{JL}$, Kleiger R, Miller JP, Rolnitzky LM. The relationships among ventricular arrhythmias, left ventricular dysfunction, and mortality in the 2 years after myocardial infarction. Circulation. 1984;69(2):250-8. doi:10.1161/01.CIR.69.2.250

25. Myerburg RJ. Implantable cardioverter-defibrillators after myocardial infarction. N Engl J Med. 2008;359(21):2245-53. doi:10.1056/NEJMra0803409.

26. Bello D, Fieno DS, Kim RJ, Pereles FS, Passman R, Song G, Kadish AH, Goldberger JJ. Infarct morphology identifies patients with substrate for sustained ventricular tachycardia. J Am Coll Cardiol. 2005;45(7):1104-8. doi:10.1016/j.jacc.2004.12.057.

27. Hohnloser SH, Kuck KH, Dorian P, Roberts RS, Hampton JR, Hatala R, Fain E, Gent M, Connolly SJ. Prophylactic use of an implantable cardioverterdefibrillator after acute myocardial infarction. N Engl J Med. 2004;351 (24):2481-8. doi:10.1056/NEJMoa041489.

28. Fernandes VR, Wu KC, Rosen BD, Schmidt A, Lardo AC, Osman N, Halperin HR, Tomaselli G, Berger R, Bluemke DA, Marban E, Lima JA. Enhanced infarct border zone function and altered mechanical activation predict inducibility of monomorphic ventricular tachycardia in patients with ischemic cardiomyopathy. Radiology. 2007;245(3):712-19. doi:10.1148/ radiol.2452061615.

29. Melillo G, Lima JA, Judd RM, Goldschmidt-Clermont PJ, Silverman HS. Intrinsic myocyte dysfunction and tyrosine kinase pathway activation underlie the impaired wall thickening of adjacent regions during postinfarct left ventricular remodeling. Circulation. 1996;93(7):1447-58.

30. Bogen DK, Rabinowitz SA, Needleman A, McMahon TA, Abelmann WH. An analysis of the mechanical disadvantage of myocardial infarction in the canine left ventricle. Circ Res. 1980;47(5):728-41.

31. Hung C-L VA, Uno $H$, et al. Longitudinal and circumferential strain rate, left ventricular remodeling, and prognosis after myocardial infarction. Am J Cardiol. 2010;56:1812-22. doi:10.1016/j.jacc.2010.06.044.

\section{doi:10.1186/1532-429X-14-24}

Cite this article as: Schuleri et al: Cardiovascular magnetic resonance characterization of peri-infarct zone remodeling following myocardial infarction. Journal of Cardiovascular Magnetic Resonance 2012 14:24.

\section{Submit your next manuscript to BioMed Central and take full advantage of:}

- Convenient online submission

- Thorough peer review

- No space constraints or color figure charges

- Immediate publication on acceptance

- Inclusion in PubMed, CAS, Scopus and Google Scholar

- Research which is freely available for redistribution

Submit your manuscript at www.biomedcentral.com/submit
C Biomed Central 